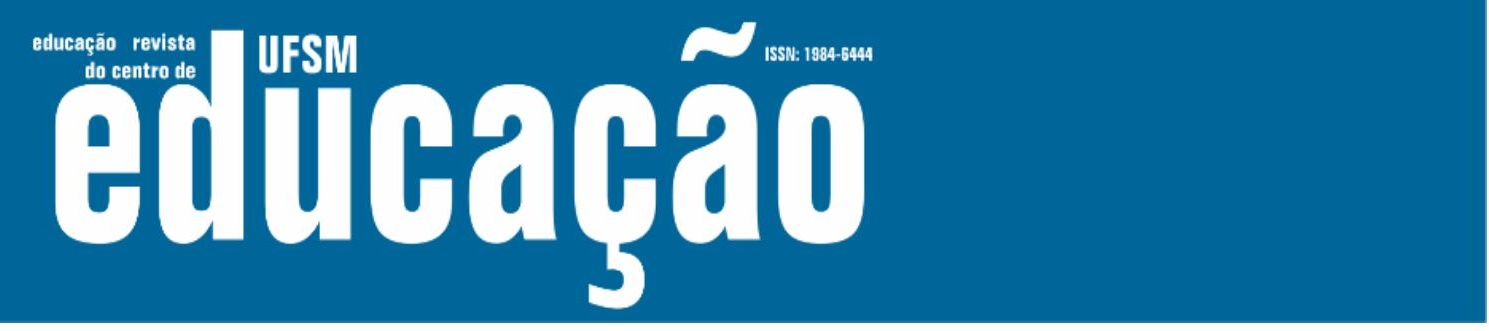

ISSN: 1984-6444 | http://dx.doi.org/10.5902/1984644438743

\title{
Cores que desenham o mundo: infâncias e as marcas de gênero, raça e classe
}

\author{
Colors that design the world: childhoods and marks of gender, race and \\ class
}

Artur Oriel Pereira

Mestrando na Universidade Estadual de Campinas. Campinas, São Paulo. Brasil. arturoriel@gmail.com - https://orcid.org/0000-0001-7307-878X

Flavio Santiago

Pesquisador na Universidade Estadual de Campinas. Campinas, São Paulo. Brasil.

flavio.fravinho@gmail.com - https://orcid.org/0000-0001-7019-2042

Recebido em 26 de junho de 2019

Aprovado em 01 de outubro de 2019

Publicado em 31 de janeiro de 2020

\section{RESUMO}

$\mathrm{O}$ ato de desenhar constitui uma das expressões singulares do protagonismo infantil, reverberando a experiência de vida pela qual as crianças materializam e compartilham suas indagações frente ao mundo, atividade criadora que traz a complexidade das relações experienciadas na convivência entre elas e entre elas e com os/as adultos/as, estilos de vida e práticas culturais que deixam as marcas de sua presença. Essas marcas de experiência, por sua vez, são rastros que carregam representações que nos contam pensamentos e interpretações do que é ser uma menina ou um menino, negro/a ou branco/a e filhos/as da classe trabalhadora. Com base nos desenhos de meninas e meninos, negros/as e brancos/as, com idade entre 8 e 9 anos, procuramos compreender como as crianças do ensino fundamental concebem as infâncias vivenciadas na periferia da cidade de São Paulo - Brasil. Ao tomarmos os desenhos infantis como fonte primaria da pesquisa, os conceituamos como artefatos culturais e documentos históricos, que podem contribuir para que se reconheçam as culturas infantis expressas nos traços, símbolos e cores das criações das crianças, permitindo-nos assim pensar este momento da sociedade, com suas especificidades históricas, e as suas marcas de gênero, raça e classe social. Trata-se de uma análise interpretativa, pautada na antropologia, sociologia e pedagogia da infância.

Palavras-chave: Infâncias; Diferença; Desenho infantil.

\section{ABSTRACT}

The act of drawing is one of the singular expressions of children as protagonists, reverberating the experience of life through which children materialize and share their inquiries before the world, a creative activity that brings the complexity of the 


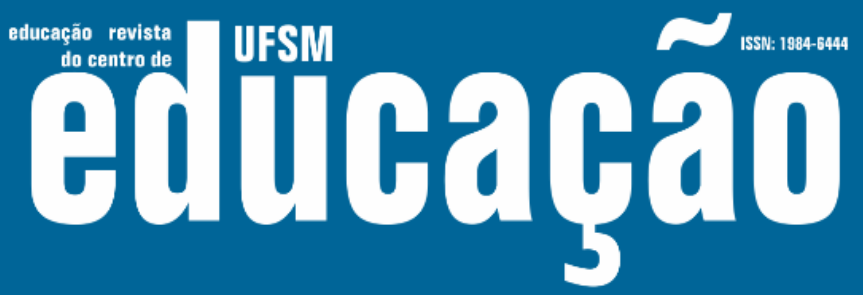

ISSN: 1984-6444 | http://dx.doi.org/10.5902/1984644438743

relationships experienced in their coexistence with other children and with adults, lifestyles and cultural practices that leave marks of their presence. These marks of experience are traces that carry representations of thoughts and interpretations of what it is like to be a girl or a boy, black or white and children of a working class. Based on the analysis of drawings by black and white boys and girls between 8 and 9 years of age we try to understand how children at elementary school conceive the image of childhoods lived in the outskirts of São Paulo City - Brazil. By taking these children's drawings as a primary source of the research, we conceptualized them as cultural artifacts and historical documents, which can contribute to the recognition of the children's culture expressed in the traces, symbols and colors of their creation, thus allowing us to think likewise about this moment of the society, with its historical specificities, and their gender, race and social class signs. This is a interpretive analysis, based on anthropology, sociology and childhood pedagogy.

Keywords: Childhood; Difference; Children's drawing.

\section{Introdução}

Inspirados nas folhas coloridas carregadas de despropósitos poéticos que fazem as palavras perderem seu poder de explicar e tornam-se enigmas, procuramos trazer os desenhos das crianças como obras, construídos por traços, símbolos e cores. Em um exercício descolonizador que valoriza as múltiplas linguagens, tivemos a preocupação de não homogeneizar ou apagar suas singularidades como também as similaridades e especificidades das infâncias.

Partimos da perspectiva que as crianças são atores e atrizes sociais, construtoras da sociedade, brincando, falando, desenhando, chorando, interagindo com as adultas e adultos e com crianças de várias idades por meio de diferentes formas de expressão, consolidando o seu papel ativo no processo de ação social, desmistificando perspectivas que as concebem como seres passivos e receptores na sociedade ${ }^{1}$.

O espaço de criação dos desenhos que trazemos nesse trabalho é o de uma turma do $3^{\circ}$ ano do ensino fundamental I em uma escola pública da rede municipal de ensino localizada em um bairro de operários/as na região leste da cidade de São Paulo. No entorno da escola, há residências construídas de forma planejada, com ruas largas e praças. Por conta de uma grande quantidade de praças, o bairro torna-se um 


\section{Eutha \\ ISSN: $1984-6444$}

ISSN: 1984-6444 | http://dx.doi.org/10.5902/1984644438743

dos mais arborizados do munícipio. As famílias das crianças matriculadas nessa escola, em sua maioria, residem no bairro e trabalham em outra região da cidade. Os 7 desenhos que aqui apresentamos são das meninas e meninos que deram o aceite para participar da pesquisa, e é parte de uma documentação pedagógica de um grupo infantil de 25 crianças. A ideia é trazer a visibilidade para as (das) meninas e os (dos) meninos, suas produções e a diversidade. ${ }^{2}$

Tabela 1: O grupo infantil.

\begin{tabular}{cccccc}
\hline & \multicolumn{2}{c}{ Meninas } & \multicolumn{2}{c}{ Meninos } \\
\hline Idade & Negras & Brancas & Negros & Brancos \\
\hline $\mathbf{8}$ anos & 1 & 3 & 1 & 5 \\
\hline $\mathbf{9}$ anos & 1 & 6 & 2 & 6 \\
\hline Total & & 11 & & & 14
\end{tabular}

Fonte: Tabela elaborado pelos autores (2018).

A escolha de trazer os desenhos das crianças dessa turma foi pautada no interesse em compreender o que as meninas e meninos têm a nos dizer frente ao mundo, para isso é preciso estar entre elas, conversar e escutá-las, sobretudo, ter como prioridade a construção de relações horizontalizadas na escola. O desafio também é romper com a separação entre teoria e prática, entre o educador na escola e o pesquisador na universidade, pois a identidade profissional aqui não é vista em termos abstratos, mas em contextos, em relação aos parceiros de trabalho educativo, acima de tudo, às crianças, suas famílias, mas também em relação à própria formação pessoal, profissional e educacional, além da experiência (RINALDI, 2012), "conectando teoria e prática para superar tanto a ideia de uma ordem hierárquica, quanto a ideia de prática como tradução operacional das teorias" (INFANTINO; ZUCCOLI, 2016, p. 44-45) comumente difundida.

Em diferentes momentos do horário escolar, como parte do dia a dia, observamos que as meninas e os meninos compartilharam suas experiências. Muitas vezes, as crianças conversaram sobre os jogos e brincadeiras, os filmes assistidos e 


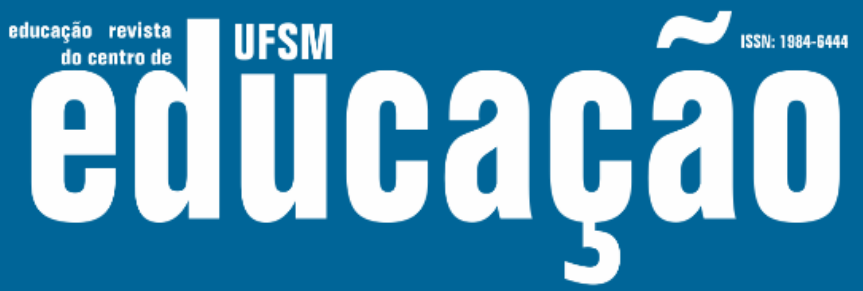

ISSN: 1984-6444 | http://dx.doi.org/10.5902/1984644438743

comentados na sala de vídeo, os estudos do meio realizados nos jardins e espaços arborizados, as brincadeiras no parque da escola, as atividades durante as aulas de educação física, como também das suas relações com outras/os professoras/es e seus familiares.

Concebemos que nos anos iniciais do ensino fundamental não se deve apressar, tampouco, sufocar as experiências que acontecem no presente. $\mathrm{Na}$ contramão de uma percepção colonial de alfabetização que antecipa mecanicamente os conteúdos e as aprendizagens escolares definidas a priori, assim como da tríade ler, escrever e fazer contas que, precocemente permeia o processo educativo das crianças, "didatizando a experiência das crianças no mundo". Como destacam Quinteiro e Carvalho (2016) o direito à infância na escola deve ser entendido como uma perspectiva de mudança educacional radical e não deve ser confundido nem limitado à ampliação nem à antecipação da escolaridade obrigatória.

Ao término da atividade prevista no cronograma escolar, disponibilizamos para as crianças diversos materiais como papel branco, giz de cera, lápis preto, de cor e de diversos tons de pele, para que as meninas e os meninos criassem obras nos papéis que expressassem pensamentos, modos de ver, sentir e estar no mundo. Caso as crianças quisessem, elas podiam ou não entregar suas criações, pois não havia como não há imposições no planejamento, alguns colaram os desenhos em seus cadernos, já as crianças participantes quiseram entregar o desenho para os pesquisadores e compartilhar os significados ali representados.

Durante esses momentos a observação e o entrosamento com a turma foi fundamental para o processo da pesquisa. O conhecimento foi construído na interação entre todas/os, aberto a possibilidade de conhecer e conhecer-se, para além do currículo escolar e dos pertencimentos culturais. Desse modo, na análise dos desenhos levamos em conta a perspectiva das crianças, aliando desenho e oralidade (cf. Gobbi, 1997), considerando as experiências narradas e interpretadas a partir delas. "Desenhos são para a gente folhear, são para serem lidos que nem poesias, são haicais, são rubaes, são quadrinhas e sonetos" (ANDRADE, 1975, p. 77). Assim, o foco da nossa análise está ligado aos conteúdos expressos por eles em seus 


\section{Autตaดูão}

ISSN: 1984-6444 | http://dx.doi.org/10.5902/1984644438743

desenhos, tomamos as obras construídas pelas crianças enquanto documentos que expressam as condições materiais, suas realidades e seus saberes (GOBBI, 1997).

É fundamental destacarmos que a conjuntura de produção dos desenhos das crianças é o recente ao golpe de Estado de 2016 no Brasil, a favor dos interesses do capital e que ameaça à democracia e os direitos sociais, no qual a temática relativa às relações de gênero e a diversidade sexual é descartada e retirada da Base Nacional Comum Curricular. Quinze anos após a promulgação da lei № 10.639/2003 que versa sobre a obrigatoriedade do ensino de História e Cultura Afro-Brasileira no Ensino Fundamental e Médio, já existindo inúmeros trabalhos desenvolvidos na educação básica acerca da promoção da educação para as relações étnico-raciais, bem como os/as professores/as terem recebido formação continuada.

Os conhecimentos sobre a criação de desenhos pelas crianças, abordando aspectos das artes visuais, das ciências sociais - ao conceber o desenho como documento histórico - em consonância com a pedagogia, considerando as especificidades da primeira infância defendida por Gobbi (1997), reconhece que as crianças são sujeitos produtores de culturas infantis, e aponta que os desenhos infantis são verdadeiros documentos produzidos pelas crianças e que a partir deles podemos conhecer suas realidades vividas.

Dessa maneira, conceituamos os desenhos das crianças como expressões singulares do protagonismo infantil, artefatos culturais e documentos históricos que materializam a experiência de vida pela qual crianças demonstram suas indagações frente ao mundo. Ao tratar os desenhos das crianças com essa peculiaridade, Gobbi (2014, p. 154) destaca que isso "não significa que possam ser vistos como cópias da realidade [...]. Como verdade iconográfica, não é expressão de neutralidade ou do todo ali representado. É invenção, fantasia, guarda elementos da imaginação, [...] do cotidiano vivido e sentido pelas meninas e meninos". Nessa dinâmica, a cultura opera como rede simbólica baseada na experiência vivenciada, experimentada e concebida, pois as relações imprimem ao olhar e à percepção dos sujeitos, esquemas de valores que orientam as posturas de uns sobre os outros (GUSMÃO, 1999).

Como tal, o desenho infantil é uma atividade criadora que carrega a complexidade das relações experienciadas na convivência entre diferentes sujeitos 


\section{F HEM

ISSN: 1984-6444 | http://dx.doi.org/10.5902/1984644438743

em sociedade. Desse modo, sua compreensão "implica a construção de olhares rigorosos, minuciosos e práticas reflexivas sobre as relações sociais e como as crianças ordenam sua percepção de mundo e nos apresentam em seus traçados e assuntos selecionados" (GOBBI, 2014, p. 155) outro ponto de vista histórico e social, e as lógicas de construção de culturas naquilo que caracteriza a infância.

Os desenhos estabelecem uma relação de correspondência com a realidade e com signos gráficos: contudo, não são meras representações, mas sim formas que podem funcionar como equivalentes pictóricos. Para Mário de Andrade, como destaca Faria (1999), os desenhos não representam a eternidade, mas a verificação de um momento, assim como a dança, os desenhos fazem parte das artes intermediárias entre as artes do espaço e as artes do tempo. O processo de criação não é a reprodução, mas sim a construção de um mundo diverso: de um mundo transitório, é uma espécie de ponte ilusória, mas não menos real, é jogo pelo qual podemos compartilhar nossas experiências através da arte (GALANTI, 2016).

As crianças ao desenharem traçam o mundo pelo seu olhar, sendo esse ato uma das formas de materialização simbólica das culturas infantis, trazendo para suas construções os conflitos existentes nos espaços em que convivem. Para pensarmos esse ponto de criação artísticas das crianças, é preciso compreender que os aspectos inovadores e criativos da participação infantil na construção da realidade social, destacando as formas particulares das crianças criarem e participarem das culturas infantis, não se limitam a introjetar a sociedade e a cultura, mas contribuem ativamente para a produção e mudança cultural.

As culturas infantis são produzidas por meio das diferentes relações que as crianças estabelecem com o mundo, trazendo também para suas construções os conflitos existentes nos espaços em que convive, um elemento que é extremamente positivo. Como afirma Corsaro (2011), esses processos são estabelecidos por meio da reprodução interpretativa. Segundo o autor, o termo interpretativo engloba aspectos que tangem a participação infantil na sociedade, tais como: a inovação e a criatividade. Outro ponto seria o termo "reprodução" que agrega a ideia de que as crianças não se limitam a internalizar a sociedade e a cultura, mas, contribuem ativamente para a produção de mudanças sociais, ao mesmo tempo em que também 


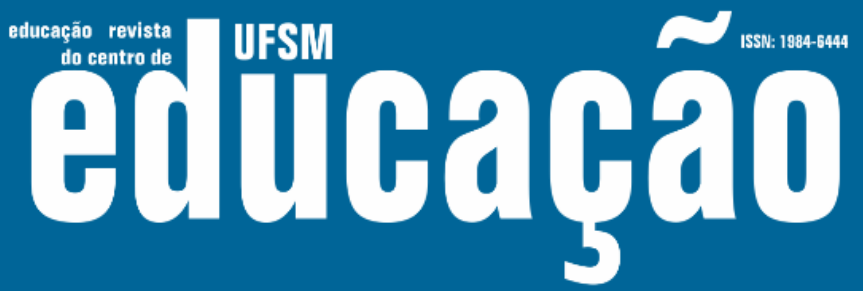

ISSN: 1984-6444 | http://dx.doi.org/10.5902/1984644438743

estão, por sua própria atuação na sociedade, restritas pela estrutura social existente e pela reprodução social.

Ao encontro desse pensamento, "as culturas infantis não se constroem no vazio; elas são um dos componentes da totalidade estando em relação direta com o que é produzido pelos jovens, adultos/as e velhos" (MACEDO, 2016, p. 102). Logo, a criança e as infâncias desafiam a compreensão de si mesmas ante a cultura tradicional com seus modelos determinados, pois nem sempre as infâncias e as crianças correspondem ao que delas se pensa ou se espera. Suas potencialidades, por vezes, desafiadoras do mundo adulto (GUSMÃO, 1999).

\section{Culturas infantis e as marcas de gênero, raça e classe}

As imagens que se seguem revelam marcas de experiência que deixam sua presença. Essas marcas, por sua vez, são rastros que carregam valores sociais e significados que falam da vida cotidiana em sociedade, da forma como as crianças se classificam e se reconhecem, interagem com a natureza, as adultas e adultos e seus as outras crianças. As brincadeiras, enquanto elementos das culturas infantis caracterizam os grupos das crianças, determinam, também, sua estrutura e organização. Nas brincadeiras alguns padrões sociais de conduta da cultura adulta tradicional são praticados, só que as crianças não são levadas a imitar indivíduos, mas a adquirir padrões de comportamento correspondentes a certas funções sociais (FERNANDES, 2004).

Como podemos verificar nos desenhos de João, Marta e Tobias a infância, quer seja no espaço da escola ou não, é retratada como o momento da brincadeira, da interação entre as crianças, estando explicitado ou explicitada a relação desse momento da vida com o lúdico, no entanto, muitas vezes, marcado pelas divisões binárias das relações de gênero. 


\section{Uism

ISSN: 1984-6444 | http://dx.doi.org/10.5902/1984644438743

Desenho 1 - João, 9 anos, branco. "São as crianças brincando!".

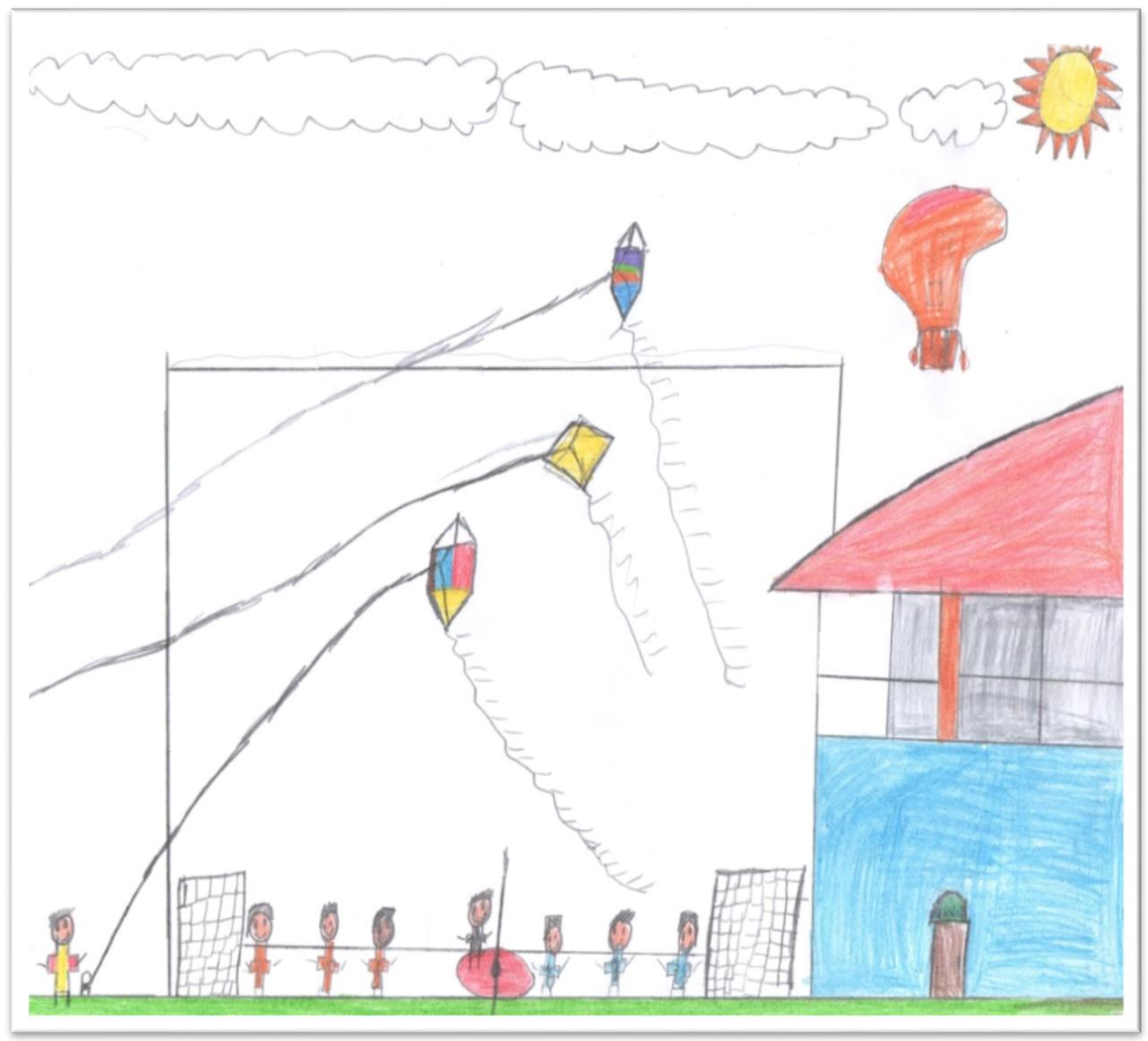

Fonte: Acervo dos autores (2018).

O desenho do João relacionado aos meninos mostra atividades como correr, jogar bola com outros colegas, empinar pipas, voar de balão dirigível. Diferente do desenho da Marta, que expressa o cuidado com o corpo e a manutenção de uma aparência feminina e bela, apresentando as meninas comprando vestidos, bolsas e brincos, vestindo-se como uma princesa, brincando de ioiô com as amigas, tomando banho de sol e nadando em piscinas. 


\section{WFM

ISSN: 1984-6444 | http://dx.doi.org/10.5902/1984644438743

Desenho 2 - Marta, negra, 8 anos. "Eu fazendo compras, no restaurante, brincando de ioiô com minhas amigas e na piscina".

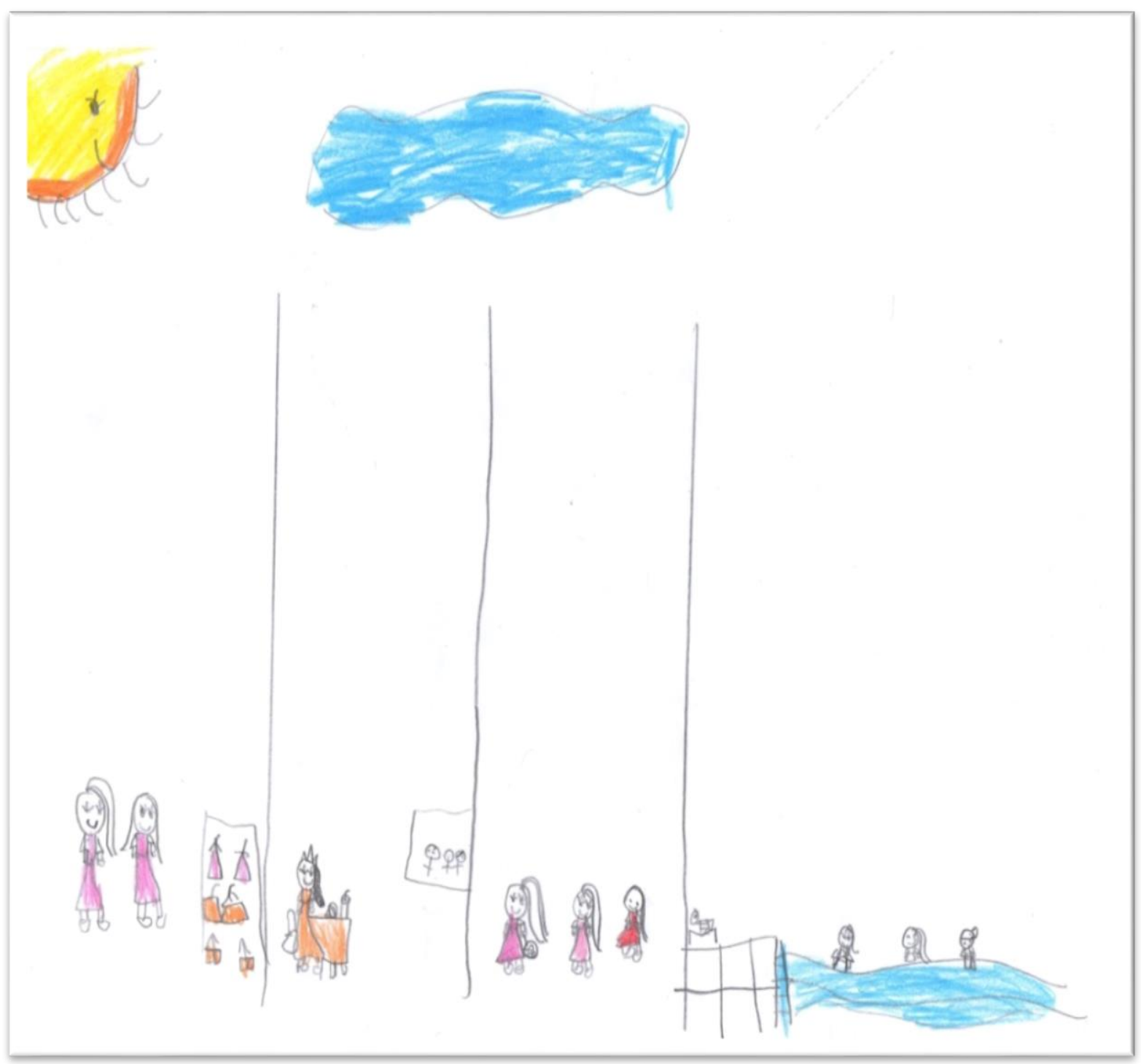

Fonte: Acervo dos autores (2018).

Faremos a reflexão entendendo esses padrões de comportamento ligados à masculinidade e a feminilidade reforçando a construção das hierarquias e diferenciações estabelecidas nas relações de gênero, e legitimando e justificando os sistemas regidos pela heteronormatividade e pelo separatismo entre os sexos. Nessa chave hierárquica a diferença sexual é convertida em diferença política, passando a se exprimir ou em liberdade ou em sujeição, e da divisão sexual do trabalho. 


\section{Fism

ISSN: 1984-6444 | http://dx.doi.org/10.5902/1984644438743

Podemos perceber, logo abaixo, no desenho e fala do Tobias, que as diferenciações de gênero estabelecidas de acordo com as práticas dos sujeitos, delimitam os lugares a serem ocupados, nas relações, nos trabalhos e nos costumes da casa e da rua. Essas concepções instituídas são aprendidas e interiorizadas cotidianamente, e acabam sendo naturalizadas. Brincar de ser minerador e construtor por meio de um jogo conectado à internet o minecraft ${ }^{3}$ em casa, andar de patinete na rua, assistir televisão e descansar no próprio quarto, será que carrega em sua concepção uma ação distintiva entre os sujeitos, separa, entre outros fatores, os meninos das meninas? Louro (2003) afirmaria que sim, pois provoca limites através de símbolos e códigos e delineia o que os sujeitos podem fazer, ou seja, constitui os espaços para meninos e meninas na estrutura da sociedade.

Desenho 3 - Tobias, branco, 9 anos. "Isso é aproveitar a vida!".

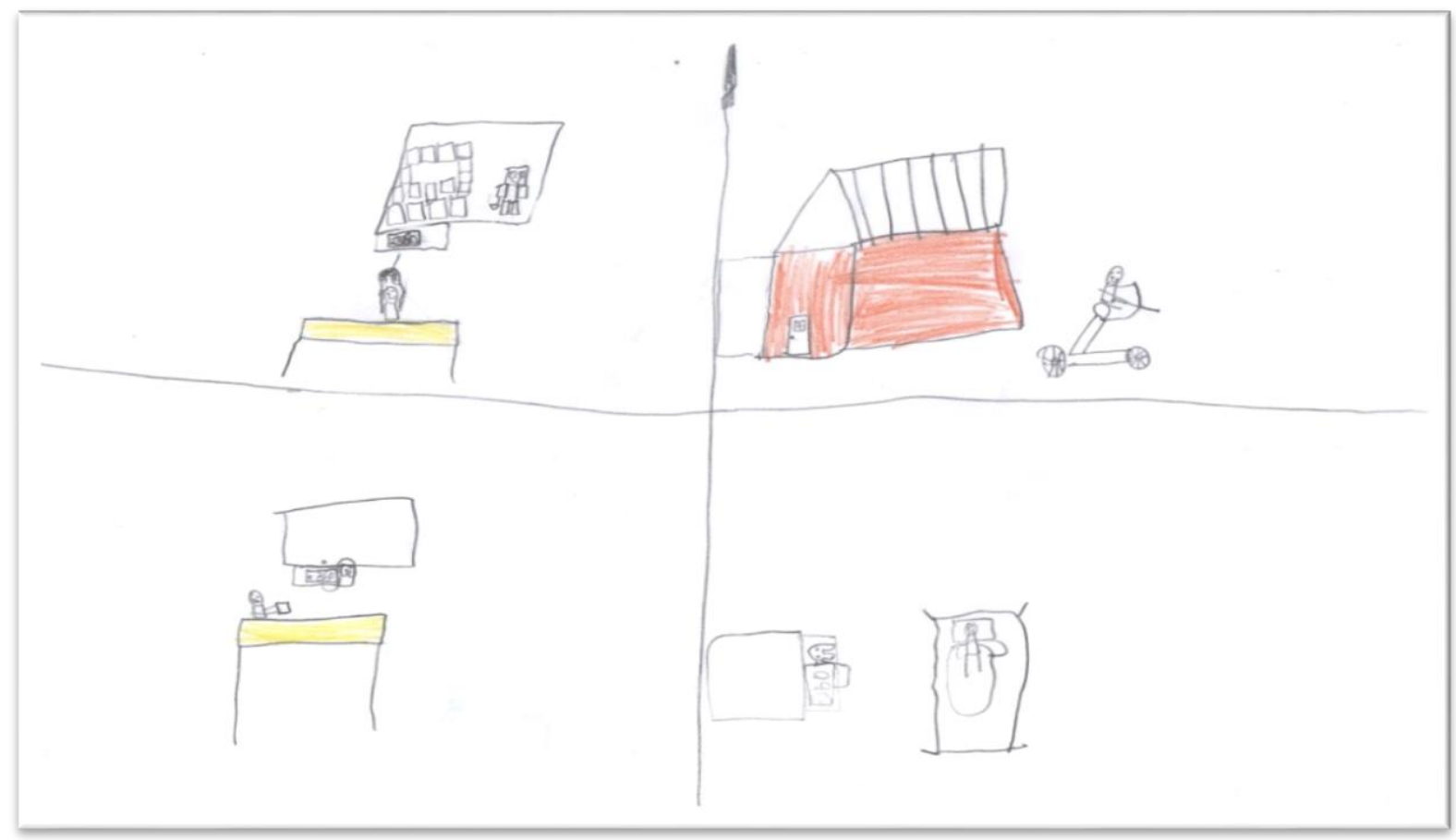

Fonte: Acervo dos autores (2018).

Essas divisões normativas das relações de gênero também são transgredidas. No desenho a seguir, José destaca durante a conversa sobre a sua criação, que ele está brincando de futebol com as meninas, ou seja, elas estão vivenciando 


\section{Uism

ISSN: 1984-6444 | http://dx.doi.org/10.5902/1984644438743

experiências no espaço escolar que antes só os meninos teriam. Como destaca Santiago (2019), as possibilidades construídas pelas crianças na relação aos/as colegas constituem espaços para a criação do novo, estabelecendo potencialidades intempestivas para a construção da vida.

As crianças redesenham as possibilidades de existência, bem como constroem a vida para além da estrutura imposta pelos padrões de gênero construídos pelo patriarcado. A cultura infantil pode ser entendida como um processo que as crianças ao serem apresentadas para alguns pressupostos, encontram sozinhas entre elas os seus posicionamentos (HENGST, 2004), os meninos e meninas são agentes sociais ativos, contribuem mutuamente para a produção da sociedade.

Desenho 4 - José, negro, 8 anos. "Aproveitando as férias".

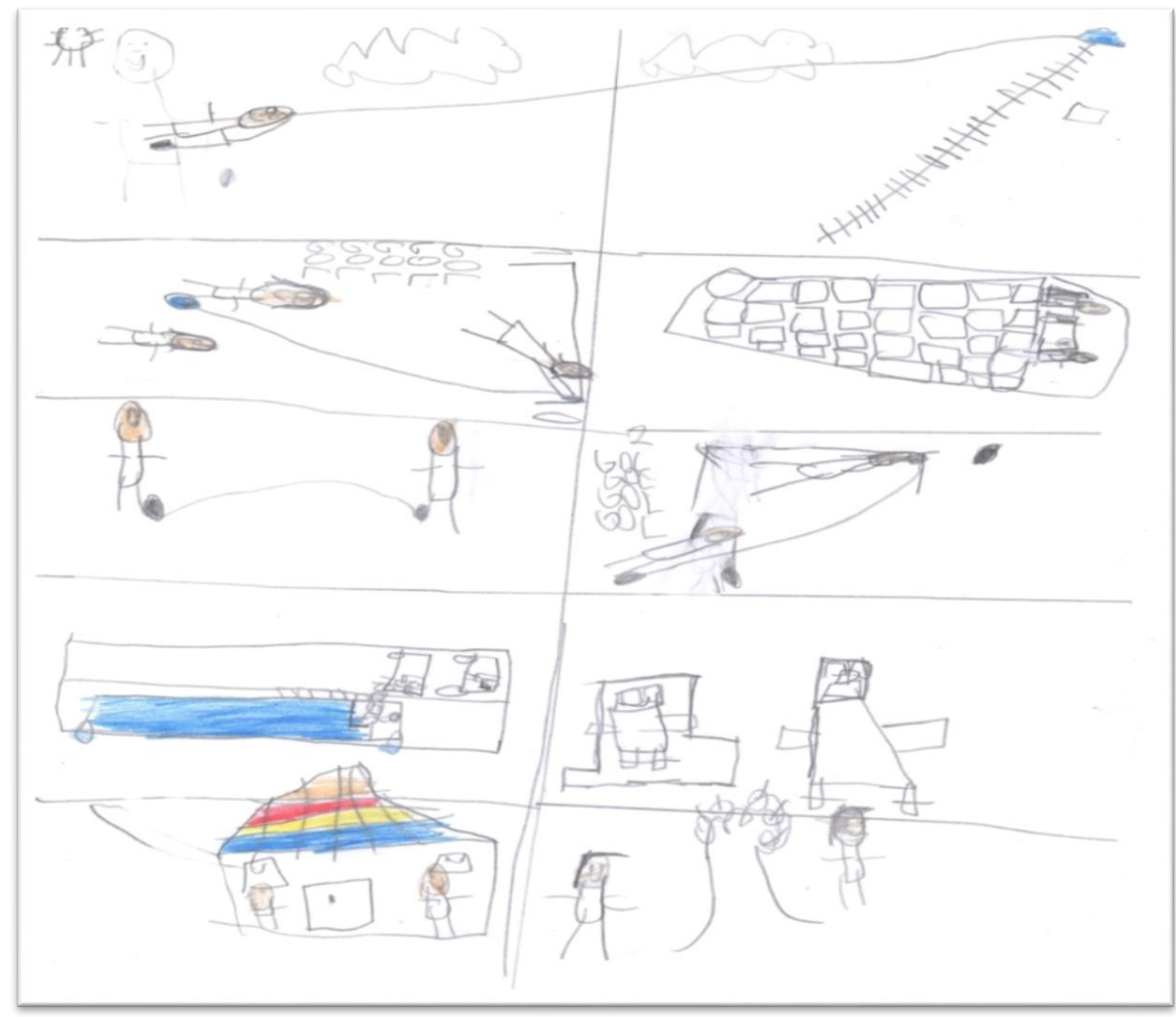

Fonte: Acervo dos autores (2018). 


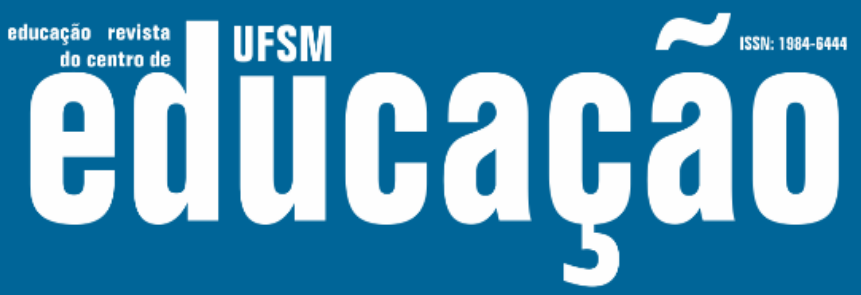

ISSN: 1984-6444 | http://dx.doi.org/10.5902/1984644438743

Todavia, o dado apresentado pelo José mostra destaca a existência de uma aceitação maior das meninas transgredirem as barreiras de gênero, daquilo que é tido socialmente como elementos e espaço do masculino. Esse aspecto pode ser observado também em todos os desenhos, pois nenhum deles apresenta meninos exercendo alguma atividade atribuída coercitivamente ao feminino na sociedade. Todavia, existe uma diferença estrutural entre a infância feminina e a infância masculina; a menina, em particular a pobre, é considerada como sendo ingênua, nãoelaborada, inferior e oriundo/a do senso comum, o lugar do nada, por isso a ela também é permitido transgredir alguns normativas imposta aos meninos, representantes do poder (ABRAMOWICZ, 1995).

Além disso, o desenho de José e sua explicação do que se tratava o desenho mostra que suas atividades carregam uma força infantil marcada pela relação ativa com o movimento, o que tensiona a organização da escola. $\mathrm{O}$ direito à infância e a brincadeira no ensino fundamental é carregado de dilemas adultocêntricos e contradições que ocorrem porque a organização do espaço, do tempo, e dos materiais, muitas vezes, não valorizam o processo, mas sim buscam resultados em dados padronizados. Como afirma Nascimento (2013, p. 160), a ideia da infância na escola vincula-se à noção de escolarização, indicada como suposta recuperação da cidadania, "essa posição, que tem como foco os conteúdos escolares [...], privilegia a cultura escolar, ou seja, o ambiente destinado ao controle e disciplinamento das crianças pelos adultos, com o objetivo de preparar as crianças para a vida futura". Frente a esse processo, as crianças pequenas criam movimentos de resistências, reivindicam gestos de ruptura contra o aceleramento do tempo do capital sobre suas vidas e demonstram o desejo de autonomia.

Nos desenhos das crianças também é perceptível o processo de embranquecimento dos sujeitos negros. Podemos observar logo abaixo, no desenho da Maria e com sua explicação, que existe uma distinção entre ser branco e ser negro, que os traços fenotípicos são codificados como elementos que constroem imaginários acerca das negras e dos negros. 


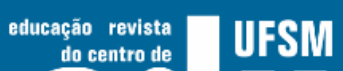

ISSN: 1984-6444 | http://dx.doi.org/10.5902/1984644438743

Desenho 5 - Maria, branca, 9 anos: "É uma menina branca e uma menina negra".

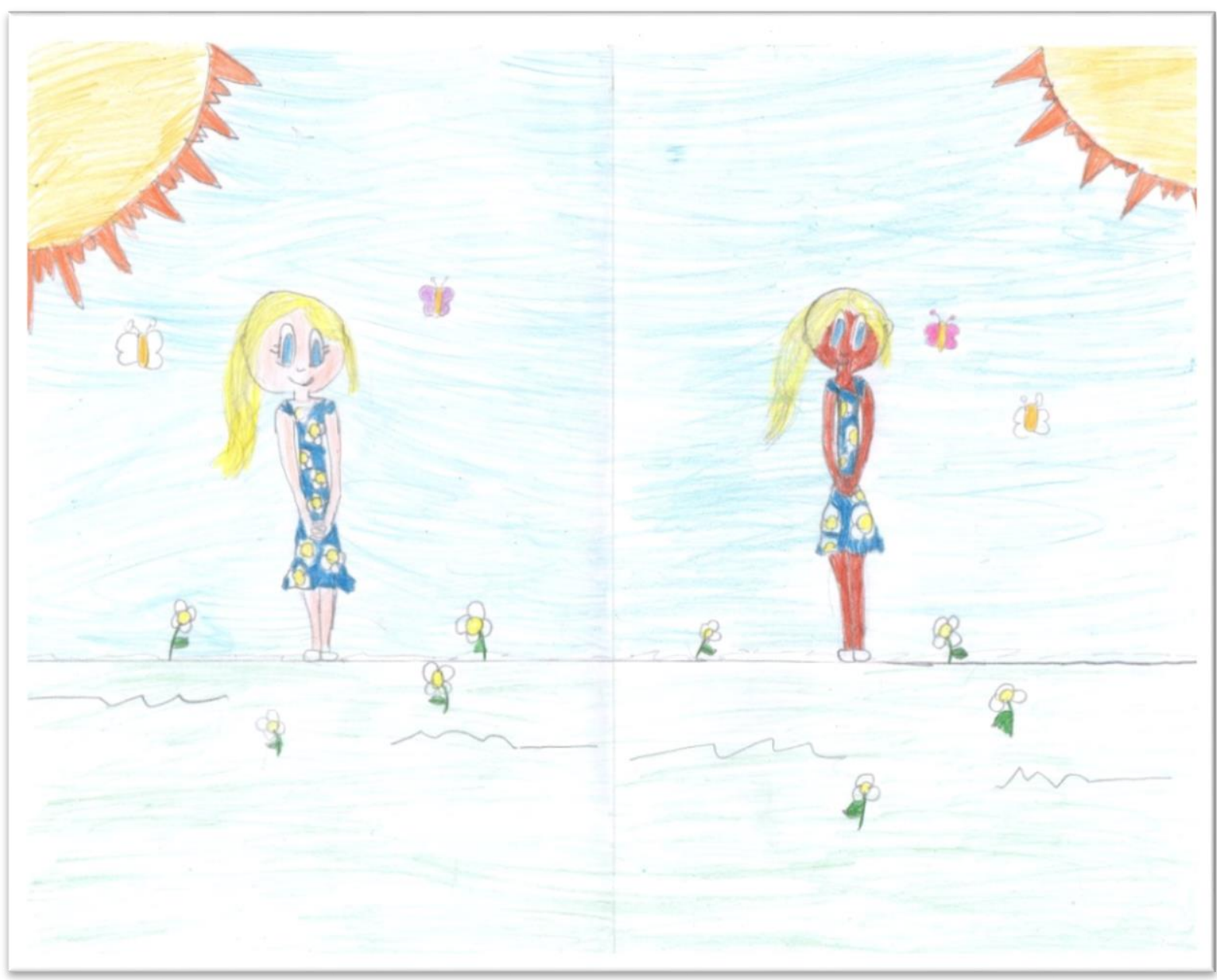

Fonte: Acervo dos autores (2018).

Dentro desse quadro, como afirma Fanon (2008), as negras e os negros são constituídos a partir de comparações ao universo relativo aos brancos, sendo entendidos enquanto os outros, aqueles que não têm fenótipos legitimados pela branquitude. A racialização divide e recorta as relações, colaborando para o reforço de estigmas, uma vez que as meninas e mulheres negras sofrem preconceitos e discriminações de maneira interseccionalizada de raça e gênero, "o peso combinado das estruturas de raça e das estruturas de gênero marginaliza as mulheres que estão na base" (CRENSHAW, 2004. p. 12). A imagem da mulher negra inclusive vista fora da interseccionalidade de gênero e raça foi construída histórica e socialmente, então, a partir desse entendimento, podemos identificar os desdobramentos dessa 


\title{
Autuaŗão
}

ISSN: 1984-6444 | http://dx.doi.org/10.5902/1984644438743

intersecção e de como a mesma afeta a vida das meninas e mulheres negras (PEREIRA, 2016; FARIAS, 2016).

Aqui, é importante destacar que, embora atualmente o conceito de interseccionalidade ganhou expressividade, a preocupação em relação ao entrelaçamento das categorias raça, gênero, classe social e sexualidade tem sido foco dos debates promovidos por feministas negras, as quais procuraram, desde a construção do processo abolicionista, construir uma luta articulada não apenas contra a opressão sexual das mulheres, mas também contra outras formas de dominação e de desigualdade baseadas no racismo. Como ressaltou Gomes (2017), na mesaredonda "Mulheres negras, resistências e interseccionalidades", no $13^{\circ}$ Congresso Mundo de Mulheres \& Seminário Internacional Fazendo Gênero 11, a articulação da categoria interseccionalidade:

\begin{abstract}
denuncia e anuncia algo mais profundo do que só saber lidar e articular as nossas diferenças de raça, classe, gênero, sexualidades, aflições, as formas como são hierarquizadas na sociedade. A interseccionalidade, na minha perspectiva, ela denuncia também o quanto esses sistemas perversos são estruturais e são estruturantes. Como eles são a raiz da opressão, do pensamento inferiorizante e violento, e retira as negras e os negros do lugar de humanidade. (informação verbal). ${ }^{4}$
\end{abstract}

O debate acerca das intersecções se insere no desafio de compreender a gênese da transformação de diferenças como elemento para justificar as desigualdades criadas pelo sistema capitalista, que privilegia um padrão de homem, de mulher, de sociedade e de sujeito social. Destaca-se também a necessidade de pensar as hierarquias sociais pautadas a partir da diferenciação por idade, o que constrói, em muitos contextos, uma invisibilidade do protagonismo das crianças (SANTIAGO, 2019).

Como destaca Akotirene (2018, p. 39), "a interseccionalidade nos instrumentaliza a enxergar a matriz colonial moderna contra os grupos tratados como oprimidos [...]". É importante ressaltar que o processo de diferenciação de grupos humanos com base em atributos classificatórios é a marca da narrativa da história ocidental. Desse modo, pesquisar as intersecções entre os marcadores sociais de diferença não representa um tema novo para a educação, mas o desafio político de 


\section{$\sim$

ISSN: 1984-6444 | http://dx.doi.org/10.5902/1984644438743

compreender como são estabelecidas as diferenciações entre os sujeitos por meio de contextos culturais e sociais (ROSEMBERG, 2014).

As teorias feministas interseccionais constituem uma alternativa revolucionária, porque são baseadas no reconhecimento do posicionamento subjetivo como ponto de partida analítico, com todas as suas variantes de gênero, classe, raça e geografia, produzindo um conhecimento em que a consideração da singularidade encarnada, da subjetividade minoritária, torna-se uma instância crítica em relação à ideia de sujeito (IANNICIELLO, 2015).

Dessa maneira,

A interseccionalidade inicia um processo de descoberta, nos alertando para o fato de que o mundo a nossa volta é sempre mais complicado e contraditório do que nós poderíamos antecipar. [...] Ela não provê orientações estanques e fixas para fazer a investigação feminista [...]. Ao invés disso, ela estimula nossa criatividade para olhar para novas e frequentemente não ortodoxas formas de fazer análises feministas. A interseccionalidade não produz uma camisa-de-força normativa para monitorar a investigação [...] na busca de uma 'linha correta'. Ao invés disso, encoraja cada acadêmica feminista a se envolver criticamente com suas próprias hipóteses seguindo os interesses de uma investigação feminista reflexiva, crítica e responsável. (DAVIS, 2008, p. 79)

Outro elemento que se intersecciona com gênero e raça são as marcas de classe, o desenho e fala de Paulo, abaixo, faz uma distinção entre os sujeitos a partir dos tons da pele, apresenta um menino negro com os cabelos pintados de loiro, como ele explica: "loiro no estilo Neymar"5 e "descalço porque não tem chuteiras" para jogar futebol. É possível observar nas periferias da Cidade de São Paulo que algumas crianças brincam nas ruas e em campos de terra, divertem-se nas condições dadas e conforme a situação socioeconômica dos seus familiares. 


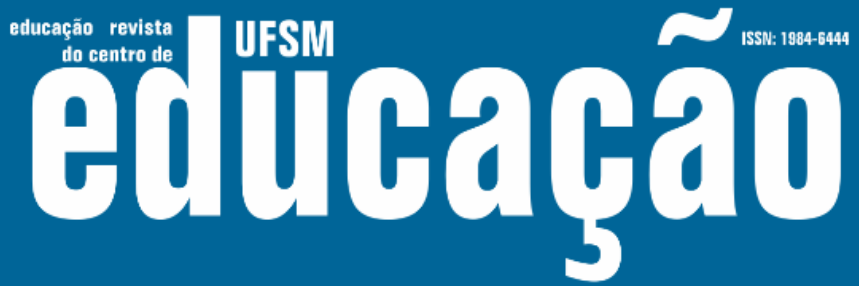

ISSN: 1984-6444 | http://dx.doi.org/10.5902/1984644438743

Desenho 6 - Paulo, negro, 9 anos: "Ser negro, ser negro mais clarinho e ser branca".

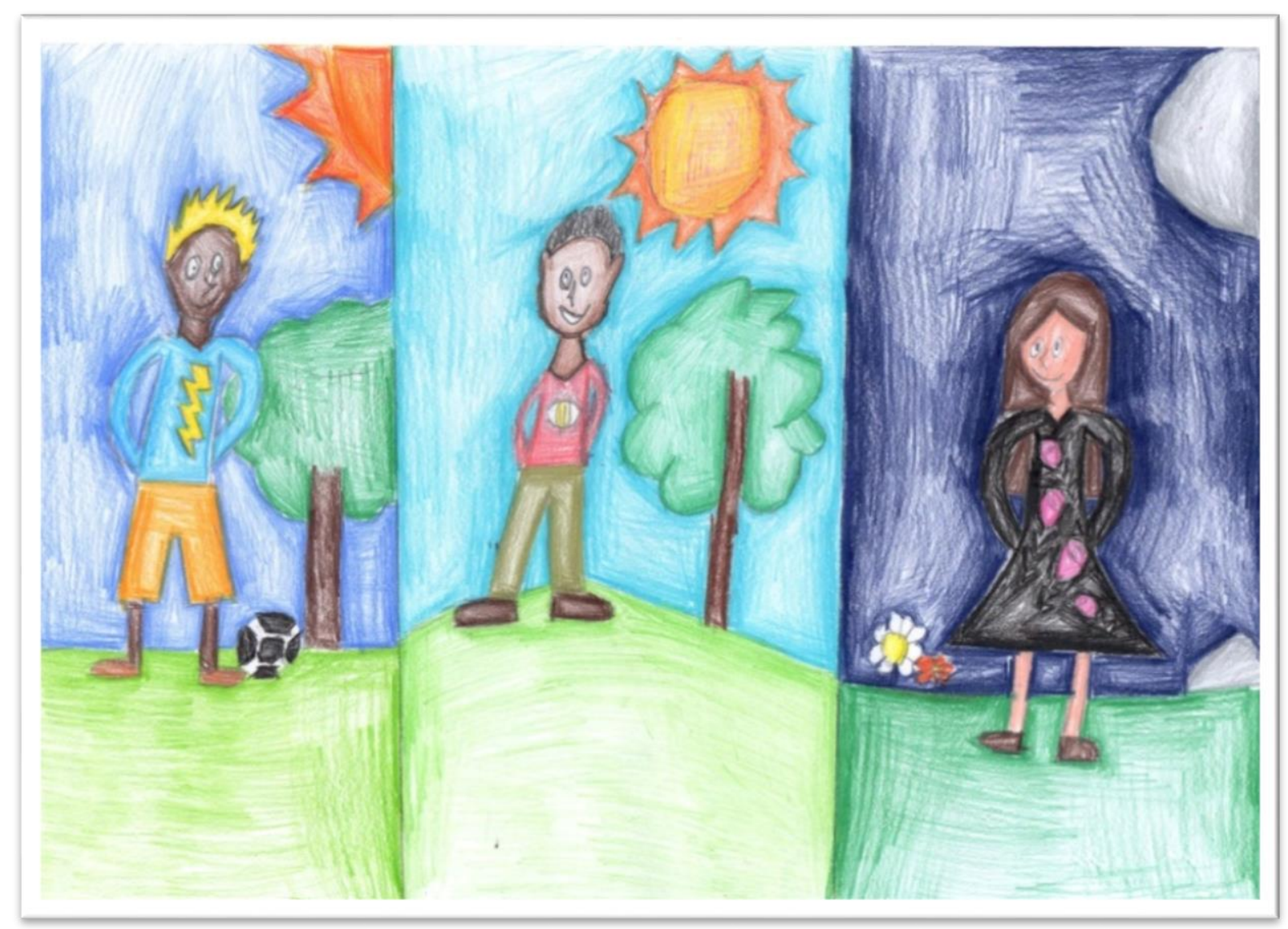

Fonte: Acervo dos autores (2018).

De certa maneira, isso retoma a gênese do período escravocrata brasileiro, onde só podiam e tinham condições de usar sapatos membros da elite e pessoas livres, a ausência de calçados era, então, uma das marcas de classe. Podemos compreender esse aspecto a partir dos requisitos estruturais de classes, que não buscou a integração de negras e de negros à sociedade e criou estratégias para justificar as desigualdades entre negros e brancos. A mudança do estatuto de escravo para homem livre, no pós-abolição, não foi acompanhada por uma efetiva integração do negro na sociedade de classes em formação. Identifica-se a continuidade e a persistência de relações sociais fundadas no período escravista (FERNANDES, 1965).

Dentre os vários aspectos com que se coteja o povo negro no contexto brasileiro, a referência à criança e à discriminação, nem sempre velada, que ela sofre, 


\section{Hism

ISSN: 1984-6444 | http://dx.doi.org/10.5902/1984644438743

tem sido alvo de estudo e denúncias daqueles que se preocupam com as questões do preconceito etc. Na contemporaneidade, esse movimento tem aumentado e se expandido com o recurso da internet. Diferentes personalidades têm utilizado esse mecanismo para atingir um grande número de pessoas, e esse advento é percebido por algumas crianças. No desenho e fala do Sandro, como veremos a seguir, ele traz a representação dos/as Youtubers ${ }^{6}$ dentro do jogo eletrônico minecraft. Ao explicar sobre a sua representação, ele disse que acompanha alguns como também brinca de ser um deles no mundo criado através desse jogo.

Desenho 7 - Sandro, branco, 8 anos. "Eles são os youtubers no minecraff".

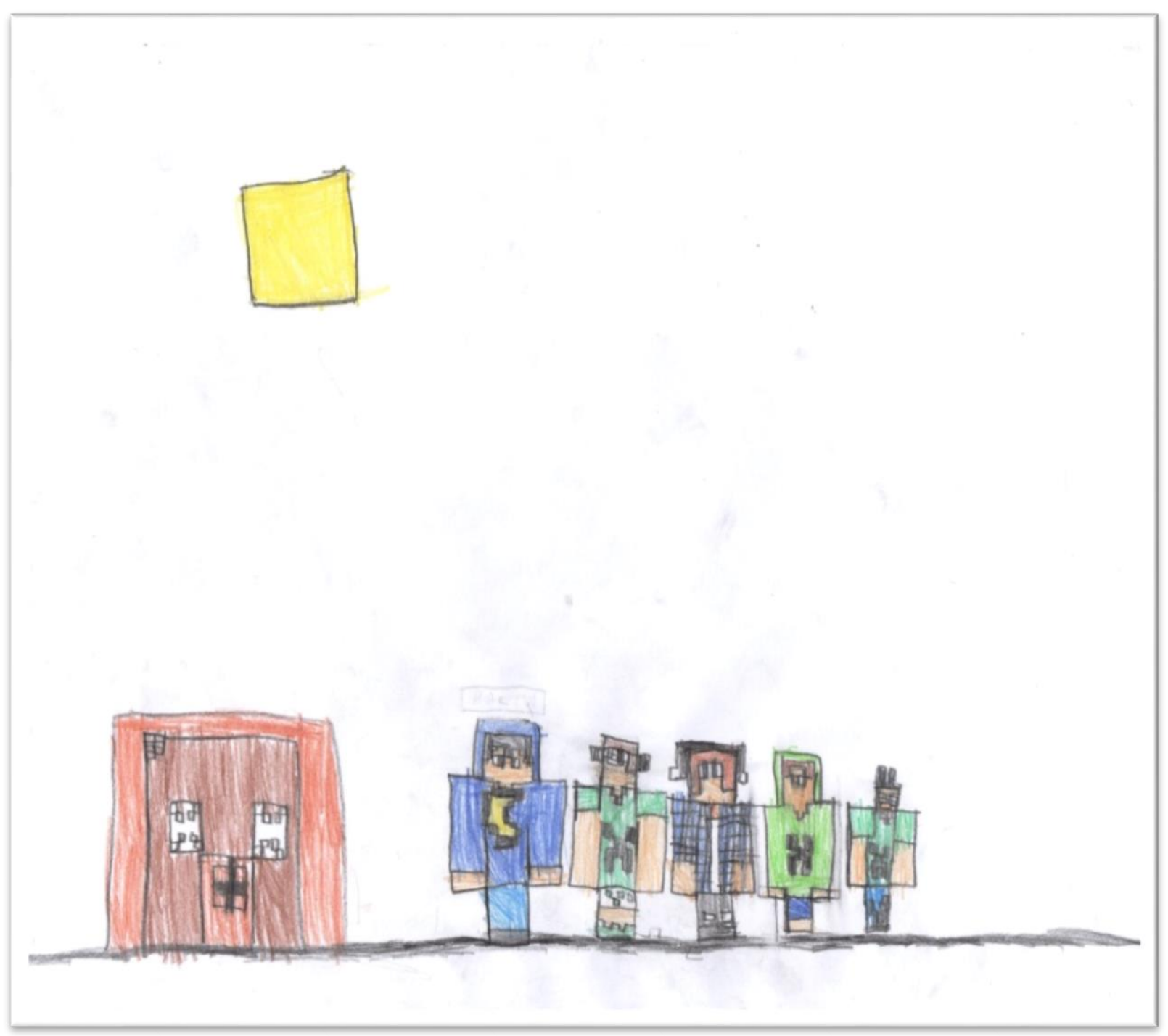

Fonte: Acervo dos autores (2018). 


\section{Autuaŗão}

ISSN: 1984-6444 | http://dx.doi.org/10.5902/1984644438743

As criações das crianças aqui apresentadas destacam a experiência, o lúdico, a imaginação, o corpo, as linguagens, nas produções das culturas infantis. Elas criam outras lógicas, novos cenários, mudam formas, personagens e enredos, e assim, produzem outros sentidos com a realidade, reinventando os sentidos propostos. Nesses mundos imaginários, as atividades familiares podem ser efetuadas de diferentes maneiras, objetos inanimados podem ser tratados como animados e as crianças podem executar uma atividade normalmente realizada por um adulto, assim como tentam resolver algumas incertezas advindas das suas interações com o mundo adulto, compartilhando-as com os colegas (CORSASO, 2011).

As culturas infantis são constituídas por elementos exclusivos das crianças, caracterizados pela natureza lúdica, cujo suporte social está no grupo infantil. Ao brincar a criança utiliza os diversos elementos da sociedade em que faz parte, produzindo cultura em um processo de apreensão criativa da cultura maior (FERNANDES, 2004). A organização interna dos grupos infantis se estabelece em função das próprias brincadeiras, e dentro dos grupos infantis, as crianças podem praticar a solidariedade e a disciplina, o respeito ou não às regras e a hierarquia em relações de interação e em função da cultura da sociedade.

\section{Desenhando o mundo...}

Ao tomarmos os desenhos infantis como fonte primaria da pesquisa, os conceituamos como artefatos culturais e documentos históricos, que podem contribuir para que se reconheçam as culturas infantis expressas nos traços, símbolos e cores das criações das crianças, permitindo-nos assim pensar este momento da sociedade, com suas especificidades históricas, suas permanências e transformações, bem como as suas marcas de idade, gênero, raça e classe social.

A partir desse quadro, o centro das preocupações nesta pesquisa trouxe à necessidade de pensar as crianças, negras e brancas, como atoras sociais localizados em um contexto social marcado pela diferenciação racial, de gênero e de idade. A infância não pode mais ser pensada de forma abstrata: 


\section{usm Autuabat

ISSN: 1984-6444 | http://dx.doi.org/10.5902/1984644438743

torna-se fundamental conceituá-la de modo interseccionado, para compreendermos a gênese da transformação de diferenças em elementos para justificar as desigualdades criadas pelo sistema capitalista, que privilegia um padrão de sociedade e de sujeito e sem dúvida excluem a/o cidadã/o de pouca idade (cf. BENJAMIN, 1984). Cabe urgente falar em interseccionalidade entre raça, classes sociais, gênero e idade (SANTIAGO; FARIA, 2018, p. 261).

As crianças ao conceberem suas infâncias vivenciadas na periferia constroem no seu cotidiano diferentes visões e propostas para sua realidade, dando um significado do que é ser menina e menino, negro/a e branco/a, da definição do seu lugar no mundo e da sua condição como agentes da transformação.

Em um movimento que valoriza as expressões de quem experimenta a vida nesse espaço social, encerramos este artigo com um trecho da canção "Fim de Semana no Parque" do grupo brasileiro de rap Racionais MC's (1993), em um exercício que procura enxergar o mundo com outros olhares:

Chegou fim de semana todos querem diversão Só alegria nós estamos no verão, mês de janeiro

São Paulo, zona sul Todo mundo à vontade, calor céu azul Eu quero aproveitar o sol Encontrar os camaradas prum basquetebol Não pega nada

Estou à 1 hora da minha quebrada Logo mais, quero ver todos em paz

Um, dois, três carros na calçada

Feliz e agitada toda playboyzada

As garagens abertas eles lavam os carros Desperdiçam a água, eles fazem a festa Vários estilos, vagabundas, motocicletas Coroa rico boca aberta, isca predileta

De verde florescente queimada sorridente A mesma vaca loura circulando como sempre

Roda a banca dos playboys do Guarujá Muitos manos se esquecem na minha não cresce

Sou assim e tô legal, até me leve a mal Malicioso e realista sou eu Mano Brown

Me dê 4 bons motivos pra não ser Olha o meu povo nas favelas e vai perceber Daqui eu vejo uma caranga do ano Toda equipada e um tiozinho guiando

Com seus filhos ao lado estão indo ao parque Eufóricos brinquedos eletrônicos Automaticamente eu imagino 


\section{usm FutlaghaO}

ISSN: 1984-6444 | http://dx.doi.org/10.5902/1984644438743

A molecada lá da área como é que tá Provavelmente correndo pra lá e pra cá Jogando bola descalços nas ruas de terra

É, brincam do jeito que dá

Gritando palavrão é o jeito deles Eles não têm videogame e às vezes nem televisão Mas todos eles têm um dom São Cosme e São Damião A única proteção

\section{Referências}

ABRAMOWICZ, Anete. A menina repetente. Campinas: Papirus, 1995.

ANDRADE, Mário. Do desenho. In: ANDRADE, Mário. Aspectos das artes plásticas no Brasil. São Paulo, Martins, 1975, p. 71-77.

AKOTIRENE, Carla. O que é interseccionalidade? Belo Horizonte: Letramento/Justificando, 2018.

BRASIL. Lei 10.639/2003, de 9 de janeiro de 2003. Altera a Lei no 9. 394, de 20 de dezembro de 1996. Diário Oficial da União, Poder Executivo, Brasília.

CORSARO, William Arnold. Sociologia da infância. 2 ed. Porto Alegre: Artmed, 2011.

CRENSHAW, Kimberlé. A interseccionalidade na discriminação de raça e gênero. In: VVAA, Cruzamento: raça e gênero. Brasília: UNIFEM, 2004, p. 7-16.

DAVIS, Kathy. Intersectionality as buzzword, a sociology of science perspective on what makes a feminist theory successful. Feminist Theory, v. 9, n. 1, p. 67-85, 2008.

FANON, Frantz. Pele negra, máscaras brancas. Salvador: EDUFBA, 2008.

FARIAS, Ana Carolina Batista de. Loira você fica muito mais bonita: relações entre crianças de uma EMEI da cidade de São Paulo e as representações étnico-raciais em seus desenhos. 2016. 158f. Dissertação (Mestrado em Educação - Sociologia da Educação). Faculdade de Educação. Universidade de São Paulo, São Paulo, 2016.

FARIA, Ana Lúcia Goulart de. A contribuição dos parques infantis de Mário de Andrade para a construção de uma pedagogia da educação infantil. Educação \& Sociedade, v. 20, p. 60-91, 1999.

FERNANDES, Florestan. A integração do negro na sociedade de classes. São Paulo: Ed. Nacional, 1965. 


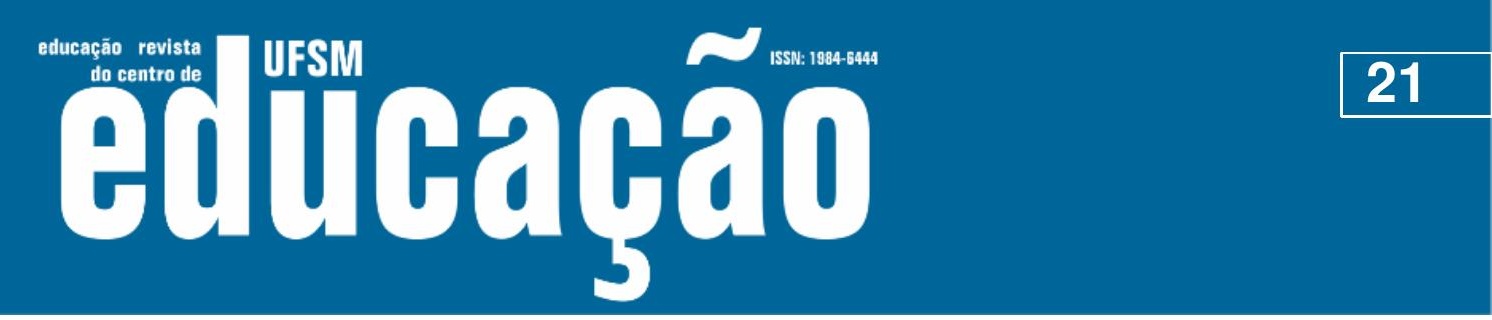

ISSN: 1984-6444 | http://dx.doi.org/10.5902/1984644438743

FERNANDES, Florestan. As trocinhas do Bom Retiro: contribuição ao estudo folclórico e sociológico da cultura e dos grupos infantis. In: FERNANDES, Florestan. Folclore e mudança social na cidade de São Paulo. São Paulo: Martins Fontes, 2004, p. 195315.

GALANTI, Maria Antonella. Immaginazione, arte e creatività nell'età del nido. In: MANTOVANI, Susanna; SILVA, Clara; FRESCHI, Enrica. (orgs.) Didattica e nido d'infanzia: metodi e pratiche d'intervento educativo. Milano: Edizioni Junior/Gruppo Spaggiari, 2016, p. 169-189.

GOBBI, Márcia Aparecida. Lápis vermelho é de mulherzinha: desenho infantil, relações de gênero e educação infantil. Dissertação. 1997. 157f. Dissertação (Mestrado em Educação). Faculdade de Educação. Universidade Estadual de Campinas, Campinas, 1997.

GOBBI, Márcia Aparecida. Mundos na ponta do lápis: desenhos de crianças pequenas ou de como estranhar o familiar quando o assunto é criação infantil. Linhas Críticas, Brasília, DF, v. 20, n. 41, p. 147-165, jan./abr. 2014.

GUSMÃO, Neusa Maria Mendes de. Linguagem, cultura e alteridade: imagens do outro. Cadernos de Pesquisa, n 107, p. 41-78, julho/1999.

HENGST, Heinz. Modelli d'infanzia nelle transformazioni sociocultural di oggi. In: HENGST, Heinz; ZEIHER, Helga (Org.) Per una sociologia dell'infanzia. Milano: Franco Angeli, 2004. p. 188-207.

IANNICIELLO, Celeste. Spazi e confini, transiti e posizionamenti. In: IANNICIELLO, Celeste; QUADRARO, Michaela. Memorie transculturali: Estetica contemporanea e critica postcoloniale. Napoli: Università degli studi di Napoli “L'Orientale", 2015, p. 63-88.

INFANTINO, Agnese; ZUCCOLI, Franca. Superando a distância entre o pensamento e a prática. Pátio Educação Infantil, Porto Alegre, no 46, p. 44-48, Janeiro 2016.

LOURO, Guacira Lopes. Gênero, Sexualidade e Educação: uma perspectiva pósestruturalista. Petrópolis: Vozes, 2003.

MACEDO, Elina Elias. Crianças pequenininhas e a luta de classes. 2016. 135f. Tese (Doutorado em Educação). Faculdade de Educação. Universidade Estadual de Campinas, Campinas, UNICAMP, 2016.

NASCIMENTO, Maria Letícia Barros Pedroso. Tupi or not tupi: escolarização desde o nascimento, a quem serve? Educação não é escolarização... Principalmente quando se trata da educação da pequena infância. In: FARIA, Ana Lúcia Goulart de, et al (org.). Dossiê Infância e Educação. Leitura: Teoria \& Prática, Campinas, v. 31, n. 61 , p. 153-168, nov. 2013.

PEREIRA, Artur Oriel. Estereótipos e vieses de gênero-raça: uma análise interseccional de contos literários para crianças. 2016. 43f. Trabalho de Conclusão do 


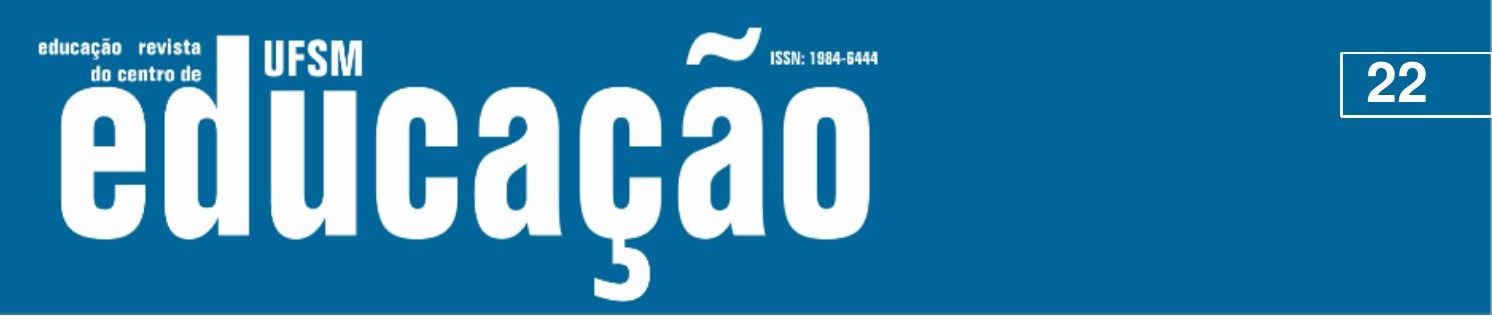

ISSN: 1984-6444 | http://dx.doi.org/10.5902/1984644438743

Curso (Licenciatura em Letras). Instituto Superior de Educação Elvira Dayrell. Faculdade do Vale Elvira Dayrell, Virginópolis/MG, FAVED, 2016.

QUINTEIRO, Jucirema; CARVALHO, Diana Carvalho de. O Ensino Fundamental de Nove anos e o Direito à Infância na Escola não são sinônimos! Revista Pedagógica, v. 17, p. 119-135, 2016.

RINALDI, Carla. Diálogos com Reggio Emilia: escutar, investigar e aprender. São Paulo: Paz e Terra, 2012.

ROSEMBERG, Fúlvia. Educação infantil e relações raciais: a tensão entre igualdade e diversidade. Caderno de Pesquisa, São Paulo, v. 44, n. 153, p. 742-759, 2014.

SANTIAGO, Flávio. Eu quero ser o Sol!: (re)interpretações das intersecções entre as relações raciais e de gênero nas culturas infantis entre as crianças de 0-3 anos em creche. 115f. Tese (Doutorado). Faculdade de Educação. Programa de PósGraduação em Educação. Universidade Estadual de Campinas, Campinas, SP, 2019.

SANTIAGO, Flávio; FARIA, Ana Lúcia Goulart de. Da descolonização do pensamento adultocêntrico à educação não sexista desde a creche: por uma pedagogia da não violência. In: TELES, Maria Amélia de Almeida; SANTIAGO, Flávio; FARIA, Ana Lúcia Goulart de (Orgs.). Por que a creche é uma luta das mulheres? Inquietações feministas já demonstram que as crianças pequenas são de responsabilidade de toda a sociedade! São Carlos: Pedro \& João Editores, 2018. p. 246-272.

\section{Correspondência}

Artur Oriel Pereira - Universidade Estadual de Campinas - Cidade Universitária Zeferino Vaz, Barão Geraldo, CEP 13083-970, Campinas, São Paulo, Brasil.

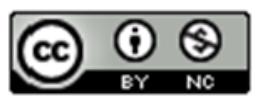

This work is licensed under a Creative Commons Attribution-NonCommercial 4.0 International (CC BY-NC 4.0)

\section{Notas}

\footnotetext{
1 Agradecemos a Ana Lúcia Goulart de Faria docente da Faculdade de Educação da Universidade Estadual de Campinas e coordenadora da linha Culturas Infantis do Grupo de Estudos e Pesquisa em Educação e Diferenciação Sociocultural, pelas trocas construídas durante a elaboração deste texto.

${ }^{2}$ Seguimos o que está previsto na Resolução CNS/MS 466/2012 e suas complementares a respeito da ética em pesquisa com seres humanos e que resguarda os direitos dos participantes, assim como o que está previsto na Lei que resguarda os direitos das crianças e adolescentes (Estatuto da Criança e do Adolescente - ECA, Lei N. ${ }^{\circ}$ 8.069/1990). Preservamos os sujeitos e utilizamos nomes fictícios na exposição dos dados, bem como não identificamos a instituição de ensino participante. A autorização do uso dos desenhos e falas concedida pelas crianças e seus/suas responsáveis encontra-se em posse dos autores. Número do parecer do Comitê de ética: 86656918.0.0000.8142
} 


\section{N

ISSN: 1984-6444 | http://dx.doi.org/10.5902/1984644438743

${ }^{3}$ Criado na Suécia em 2009 por Markus "Notch" Persson, esse jogo que tem paisagens e a maioria de seus objetos compostos por blocos que se encaixam permitindo muitas combinações, a exemplo do sistema LEGO. Basicamente, o jogador minera e constrói blocos de material virtual, uma vez que se tenha coletado e construído um inventário suficiente de recursos, usa-se as aquisições virtuais para construir casas e paisagens como também outros tipos de estruturas de blocos.

${ }^{4}$ Palestra proferida no $13^{\circ}$ Congresso Mundo de Mulheres \& Seminário Internacional Fazendo Gênero 11 Anotações e gravação realizadas em Florianópolis, 01 de agosto de 2017.

${ }^{5}$ Neymar da Silva Santos Júnior é um futebolista brasileiro que atua como ponta-esquerda defendendo o Paris Saint-Germain e a Seleção Brasileira. Aparece com frequência nos veículos da Mídia e é um dos profissionais do futebol mais famosos do mundo. Habitualmente, muda o visual lançando tendências e estilos, e este comportamento é percebido pelas crianças.

${ }^{6}$ São usuários da plataforma YouTube (serviço ligado a internet de distribuição digital de vídeos e gerenciamento de transferência de fundos) que alcançam notoriedade em sua área de atuação que pode ser ativismo, humor, música, esquete, jogos, maquiagem, dublagem, educação, arte etc., tornando-se assim celebridades. 